\title{
Impaired broiler performance as a carry-over effect in broilers fed diets naturally contaminated wtih moderate levels of deoxynivalenol
}

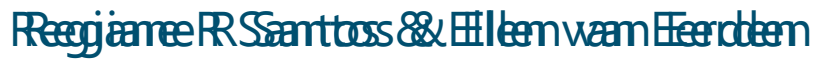

Rsantos@schothorst.nl

\section{Introduction}

- Mycotoxin exposure is common in the poultry industry. Deoxynivalenol (DON) is usually detected at levels below the maximum threshold (5,000 ppb), but depending on the diet and age, broiler performance can be affected.
- We evaluated the effects of 900 and 2,300 ppb DON on the performance of broiler chickens. Birds were fed contaminated diets up to day 28 and, from day 28 to day 35 they were fed a marginally contaminated diet.

\section{Material and Methods}

- One-day-old male Ross broilers $(n=736)$

- Four treatments, eight replicates (pen with 23 birds each)

- Days 1 - 28

- $\quad$ Low DON (LD) = 900 ppb

- LD with activated charcoal (LD+AC)

- Moderate DON (MD) =2,300 ppb

- MD with activated charcoal (MD+AC)

- Days 28-35

- $\mathrm{DON}=57.3 \mathrm{ppb}$
- Experimental diets

\begin{tabular}{|l|l|c|c|c|}
\hline & MD & $\begin{array}{c}\text { MD } \\
+ \\
\text { activated } \\
\text { charcoal }\end{array}$ & LD & $\begin{array}{c}\text { LD } \\
+ \\
\text { activated } \\
\text { charcoal }\end{array}$ \\
\hline Starter diet (D0-14) & 2060 & 2200 & 878 & 884 \\
\hline DON (ppb) & 2360 & 2220 & 941 & 811 \\
\hline Grower diet (D14-28) & & & & \\
\hline DON (ppb) & & & & \\
\hline Finisher diet (D14-28) & 57.3 & 57.3 & 57.3 & 57.3 \\
\hline DON (ppb) & 5 &
\end{tabular}

\section{Results}

Body weight gain (BWG)

D0-14

540
520
500
480
460

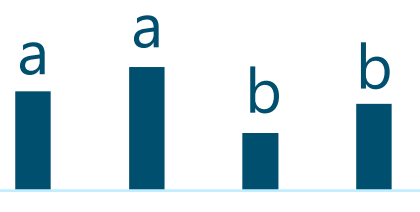

LD $\quad L D+A C \quad M D \quad M D+A C$

D28-35

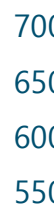

700
650
600
550

\section{Conclusion}

Impaired performance was observed in broilers fed a diet containing 2,300 ppb DON for 28 days. Although the replacement of the contaminated diet by a diet marginally contaminated with DON mitigated the negative effect of DON after 1 week, the losses related to the complete production period were not recovered. 